Article

\title{
Valuing User Preferences for Geospatial Fire Monitoring in Guatemala ${ }^{\dagger}$
}

\author{
Jared Berenter ${ }^{1}$, Isaac Morrison ${ }^{1}$ and Julie M. Mueller ${ }^{2, *}$ \\ 1 Uxeda Data Collection Resources LLC, Baltimore, MD 21218, USA; jberenter@gmail.com (J.B.); \\ uxeda1@gmail.com (I.M.) \\ 2 School of Earth and Sustainability, The W.A. Franke College of Business, Northern Arizona University, \\ Flagstaff, AZ 86011, USA \\ * Correspondence: Julie.Mueller@nau.edu \\ + The paper builds on research conducted in 2016 at the request of the United States Agency for International \\ Development (USAID) Bureau for Economic Growth, Education and Environment (E3) Analytics and \\ Evaluation Project (Contract No. AID-OAA-M-13-00017). The views and opinions expressed in this paper are \\ those of the authors and not necessarily the views and opinions of USAID.
}

check for updates

Citation: Berenter, J.; Morrison, I.; Mueller, J.M. Valuing User Preferences for Geospatial Fire Monitoring in Guatemala. Sustainability 2021, 13, 12077. https:// doi.org/10.3390/su132112077

Academic Editors: Robert P. Berrens and Benjamin A. Jones

Received: 30 May 2021

Accepted: 22 October 2021

Published: 1 November 2021

Publisher's Note: MDPI stays neutral with regard to jurisdictional claims in published maps and institutional affiliations.

Copyright: (c) 2021 by the authors. Licensee MDPI, Basel, Switzerland. This article is an open access article distributed under the terms and conditions of the Creative Commons Attribution (CC BY) license (https:// creativecommons.org/licenses/by/ $4.0 /)$.

\begin{abstract}
Like many landscapes across Central America, forests in Guatemala's Maya Biosphere Reserve (MBR) are increasingly susceptible to forest fire, with most forest fires resulting from untended agricultural fires. Fire damage poses significant risk to the MBR's natural resources and cultural heritage, but budget challenges limit the capacity of national, regional, and local institutions to effectively detect, monitor, and control forest fires. The Geospatial Information System for Fire Management (SIGMA-I) is a United States government-subsidized suite of geospatial fire management tools that are widely disseminated, free of charge, to land managers and other users in Guatemala for on-the-ground fire prevention and response. Provision of SIGMA-I geospatial data and tools such as daily thermal "hotspot" maps provide positive benefits for sustainable fire management. However, little research exists supporting the nonmarket monetary value of geospatial fire monitoring tools and their component features. We used a choice experiment to estimate land managers' willingness to pay for individual attributes of SIGMA-I hotspot mapping in Guatemala. We found quantitative evidence of positive willingness to pay for geospatial data, demonstrating positive nonmarket value of geospatial data for sustainable fire management in developing countries and regions where agricultural fires are common. Our results indicate strong preferences from Guatemala's forest fire management community for improving the frequency of hotspot reporting and reducing detection of erroneous hotspots. As the availability of geospatial data increases, use of tools like SIGMA-I has the potential to significantly improve fire management, especially in regions where funding and resources for fire management are scarce. Our results support continued multinational funding for tools like SIGMA-I for forest fire management in Guatemala and other developing countries.
\end{abstract}

Keywords: Guatemala; Maya Biosphere Reserve; geospatial; remote sensing; forest fire; hotspot; value of information; willingness to pay; choice experiment; NASA; USAID; SERVIR

\section{Introduction}

Like many tropical forest landscapes in Central America, Guatemala's northernmost department of Petén is highly susceptible to forest fires. While Petén comprises approximately a third of Guatemala's national territory, encompassing 13 municipalities and more than 800 communities, between 1998 and 2009, the region accounted for $58 \%$ of the surface area in Guatemala affected by fire [1]. Petén is also home to the Maya Biosphere Reserve (MBR), which contains more than 25,000 sq. km of protected areas with extensive historical, archaeological, biodiversity, recreational, and scenic value [2]. In recent decades, population growth and a corresponding increase in deforestation have compounded the 
forest fire risk to the natural resource base, ecosystems, and cultural patrimony of the region as a whole and of the MBR in particular [3].

To the authors' knowledge, no comprehensive empirical study of the economic cost of forest fires in Petén or the MBR has been conducted to date, but there are clear indications that the costs are significant. As of 2010, on average, more than $3500 \mathrm{sq}$. km were damaged by forest fires annually in Petén. Large-scale fires destroyed 13,086, 11,564, and $6280 \mathrm{sq} . \mathrm{km}$ of forest cover in 1998, 2003, and 2005, respectively [1]. According to Monzón-Alvarado et al., forest fires in 1998 and 2003 likely destroyed more than 30\% of the forest cover at the Laguna del Tigre and Sierra de Lacandón National Parks in the MBR. MonzónAlvarado et al. make a strong case that uncertainty caused by uncontrolled forest fires has a significant effect on long-term land use decisions in these areas [3].

In addition to destruction of forest cover, forest fire risk places a heavy burden on under-resourced local, regional, and national Guatemalan institutions responsible for battling the persistent threat of fire in the Petén region [4,5]. Guatemala's National Forest Fire Prevention and Control System (SIPECIF) reported an annual firefighting budget of 5 million quetzales (Q) during the 2015 fire season, equivalent to approximately 650,000 United States dollars (USD). This represented a significant shortfall when compared to the reported Q48 million (approximately US $\$ 6.2$ million at the time) SIPECIF requested to upgrade its prevention and response capacities that same year [6]. Popular tourist areas and highly sensitive historical sites receive some local investment to build fire breaks, but in most areas, protective breakage in vegetation is nonexistent. As a result, forest fire management in Petén relies on community compliance with burn restriction mandates, deployment of volunteer firefighters, and an early detection system managed by the Center for Monitoring and Evaluation (CEMEC) at Guatemala's National Council for Protected Areas (CONAP).

Generally, forest fire early detection systems are either terrestrial (e.g., watchtowers), airborne (e.g., manned and unmanned aircraft), or spaceborne (i.e., satellite-based) [7]. While Guatemala makes use of all three types of detection, only spaceborne detection is broadly and consistently viable across the entire MBR. Heavy forest cover in much of Petén limits the effectiveness of terrestrial observation. Daily use of either manned or unmanned aircraft is prohibitively expensive for CONAP or its disaster response agency counterpart, the Guatemala Coordinating Agency for Disaster Reduction (CONRED), and in any case is generally guided by satellite data [8]. Some limited light plane usage was reported for occasional monitoring of specific portions of the MBR such as the Laguna del Tigre National Park, but these practices are not consistent across the broader Petén region and still rely on SIGMA-1 maps for early detection of forest fires [8]. For this reason, internationally funded Earth observation tools and collaborative support from international agencies are essential to fire management and prevention in Guatemala $[9,10]$.

\section{Purpose of This Study}

This study examines the economic value of one such set of Earth observation tools and data products deployed for forest fire management in Guatemala, known as the Geospatial Information System for Fire Management (SIGMA-I), and more specifically the use of "hotspot" maps, which locate thermal anomalies in ground surface temperature representing the likelihood of a forest fire. Provision of geospatial forest fire monitoring systems like SIGMA-I is costly, and many countries, such as Guatemala, rely on governmental partnerships and international agencies for data provision. Much of the technical and financial cost of the SIGMA-I tool was borne by the US government through a joint development initiative of the National Aeronautics and Space Administration (NASA) and the United States Agency for International Development (USAID) called SERVIR Global. SERVIR Global works in partnership with leading regional organizations worldwide to help developing countries use information provided by Earth-observing satellites and geospatial technologies for managing climate risks and land use [11]. Provision of these tools thus functions as a public good for the Government of Guatemala, and its positive external benefits are not easily demonstrated using market data. 
While significant nonmarket values of geospatial data have been established in the United States, most notably for moderate-resolution imagery provided by NASA's Landsat satellites [12-14], to the authors' knowledge, no studies have examined values of attributes of geospatial mapping in developing countries. Moreover, while the application of geospatial data for forest fire monitoring is also well-established, no studies have sought to determine the economic value of geospatial monitoring tools and their attributes specifically for forest fire management. We contribute to the current literature on the use of geospatial data in fire management by estimating the value of attributes of SIGMA-I hotspot maps for end users in Guatemala. Our results provide evidence to support continued funding for SIGMA-I and similar geospatial tools for fire management and have broader implications for the positive nonmarket value of geospatial data for sustainable fire management, especially in developing countries or regions where agricultural fires are common.

\section{Materials and Methods}

\subsection{Study Area}

Forest fire risk in the MBR stems from both licit and illicit agricultural activity. As Radachowsky et al. detail, the MBR is divided into three zones: the core zone consisting of national parks and biotopes reserved for scientific investigation and low-impact tourism (and where agriculture is prohibited); the $15 \mathrm{~km}$-wide buffer zone, or zona de amortiguamiento, which spans the southern border of the MBR; and the multiuse zone (MUZ) that includes 848,440 hectares in which low-impact land uses, including agriculture, are permitted (Figure 1). Within the MUZ, CONAP relies on a system of community concessions for forest resource management. CONAP has granted 14 concessions ranging from approximately 7000 to 83,000 hectares each, covering a total of more than 500,000 hectares of the MUZ. Through these concession agreements, CONAP grants community organizations usufruct rights to timber and nontimber forest resources in the zone. In exchange, legally established community organizations must demonstrate historical use, capacity to manage forest resources sustainably, and compliance with land and resource management restrictions and best practices. Radachowsky et al. point to conservation agreements, for example, that provide incentives for communities to adhere to agricultural zoning and control deforestation and forest fires [15].

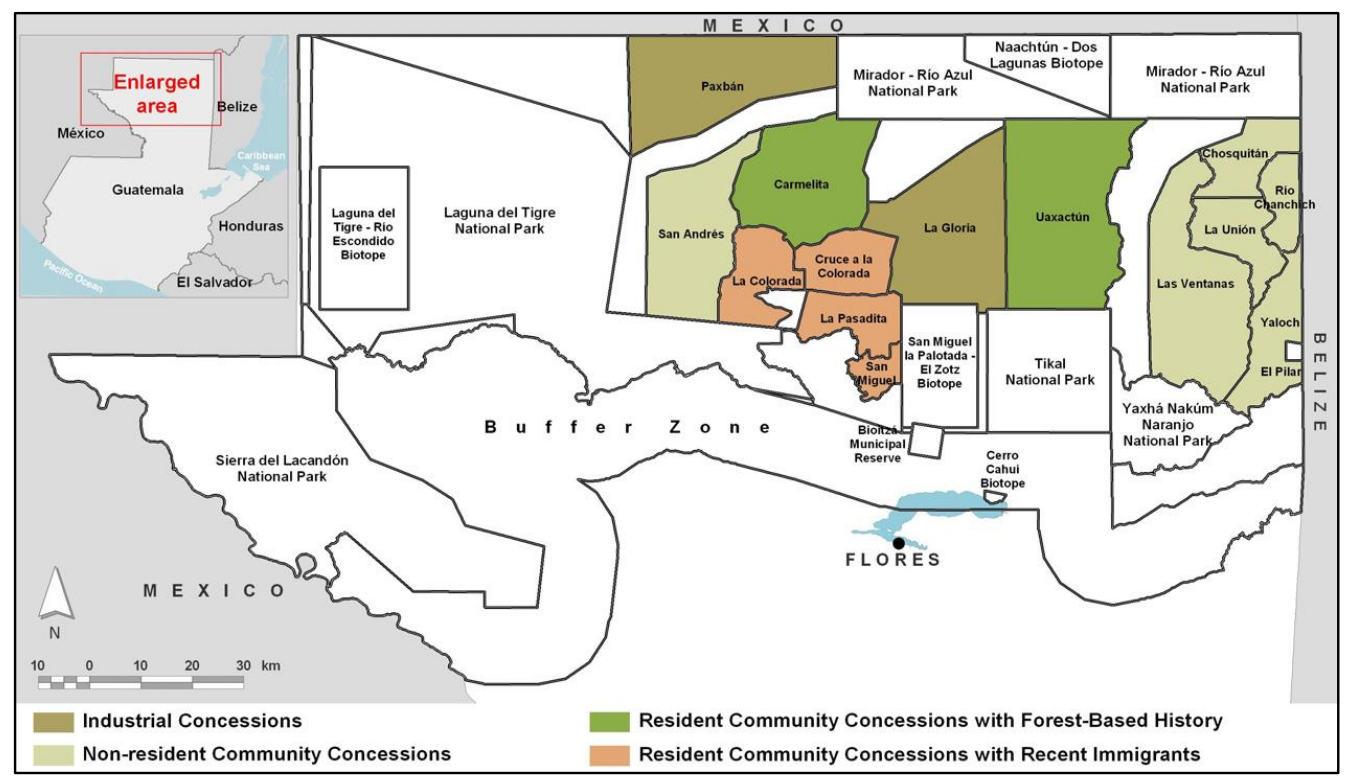

Figure 1. The Maya Biosphere Reserve in Petén, Guatemala, demarcating forest use concessions of the multiuse zone (courtesy of Radachowsky et al. [15]). 
Indeed, the main cause of forest fires in Guatemala is untended human-caused fires consistent with traditional agricultural and pastoral practices [10]. The use of fire to clear tropical forests for agricultural use further contributes to environmental degradation, thereby exacerbating fire risk management challenges in the zone [16]. Without divisions or fragmentation in the vegetation, climate conditions in the MBR are hazardous for fire for up to a third of the year, corresponding with a dry season that generally stretches from February to June.

\subsection{Geospatial Information System for Fire Management (SIGMA-I) in Petén}

The primary resource for early fire detection in Guatemala is a suite of Earth observation tools and data products known as the Geospatial Information System for Fire Management (SIGMA-I). SIGMA-I was developed by CEMEC with technical and financial support from a joint development initiative of the NASA and the USAID called SERVIR Global and is administered in collaboration with the Wildlife Conservation Society (WCS). SIGMA-I began as a series of empirical assessments of the threats posed by forest fires in Petén. Developed in 2010, these assessments relied on historical data to analyze fire scarring, fire causality, and fire risk in the MBR. They were designed to inform central-level planning decisions for forest fire management, including prioritization of municipalities with high fire-risk and allocation of resources and personnel for fire response.

\subsection{Hotspot Monitoring}

Now, the most widely used component of SIGMA-I is a fire monitoring and early warning system that produces near-real-time location data for "hotspots," or thermal anomalies in ground surface temperature (Figure 2). During the annual fire season (typically from February through June), CEMEC disseminates regional hotspot maps twice daily, free of charge, through email and WhatsApp listservs to alert key stakeholders in Guatemala's forest fire management network of likely fire activity. Recipients of the hotspot maps include first responders and government forest fire officials throughout Petén, as well as nongovernment actors such as the WCS, ProPetén, Defenders of Nature Foundation, and the University of San Carlos [17]. As will be discussed below, these hotspot maps have become deeply integrated with agricultural activities in the MBR's MUZ as agricultural burning in advance of seasonal rains, causes significant forest fire risk if not controlled [4].

The analysis presented in this study reflects the SIGMA-I features and capabilities available to users at the time the choice experiment was conducted; at that time, CEMEC relied on hotspot data gathered by Moderate Resolution Imaging Spectroradiometer (MODIS) instruments aboard NASA's Aqua and Terra satellites, which detected fires within $1 \mathrm{~km}$ "pixels"; for purposes of this choice experiment, while the quality or precision of geospatial data and data products available to first responders in the MBR has likely changed over time, categorically, the product attributes themselves have not changed. Descriptions of SIGMA-I attributes and its uses for forest fire management are in large part based on field interviews conducted by the authors in 2015 as part of a third-party performance evaluation of the SERVIR (Additional information on the use of SIGMA-I in Guatemala can be found in two SERVIR Global evaluation reports, see Supplementary Materials).

In farming communities in the MUZ, such as Uaxactún and Corozal, local fire management councils have introduced burn calendars that regulate when farmers can and cannot burn. These councils closely monitor climate conditions, notifying farmers when climate conditions are low-risk for the spread of fire so that they may proceed with scheduled agricultural burnings (Figure 3). Council officials cross-reference SIGMA-I hotspot locations with burn calendars to identify unplanned and nonpermitted burnings and dispatch response teams accordingly [18]. According to CONAP officials, deployment of first responders to verify and extinguish unplanned or nonpermitted hotspots in protected areas (by CONAP, partnering nongovernment organizations, and local first responders) is automatic [19]. 


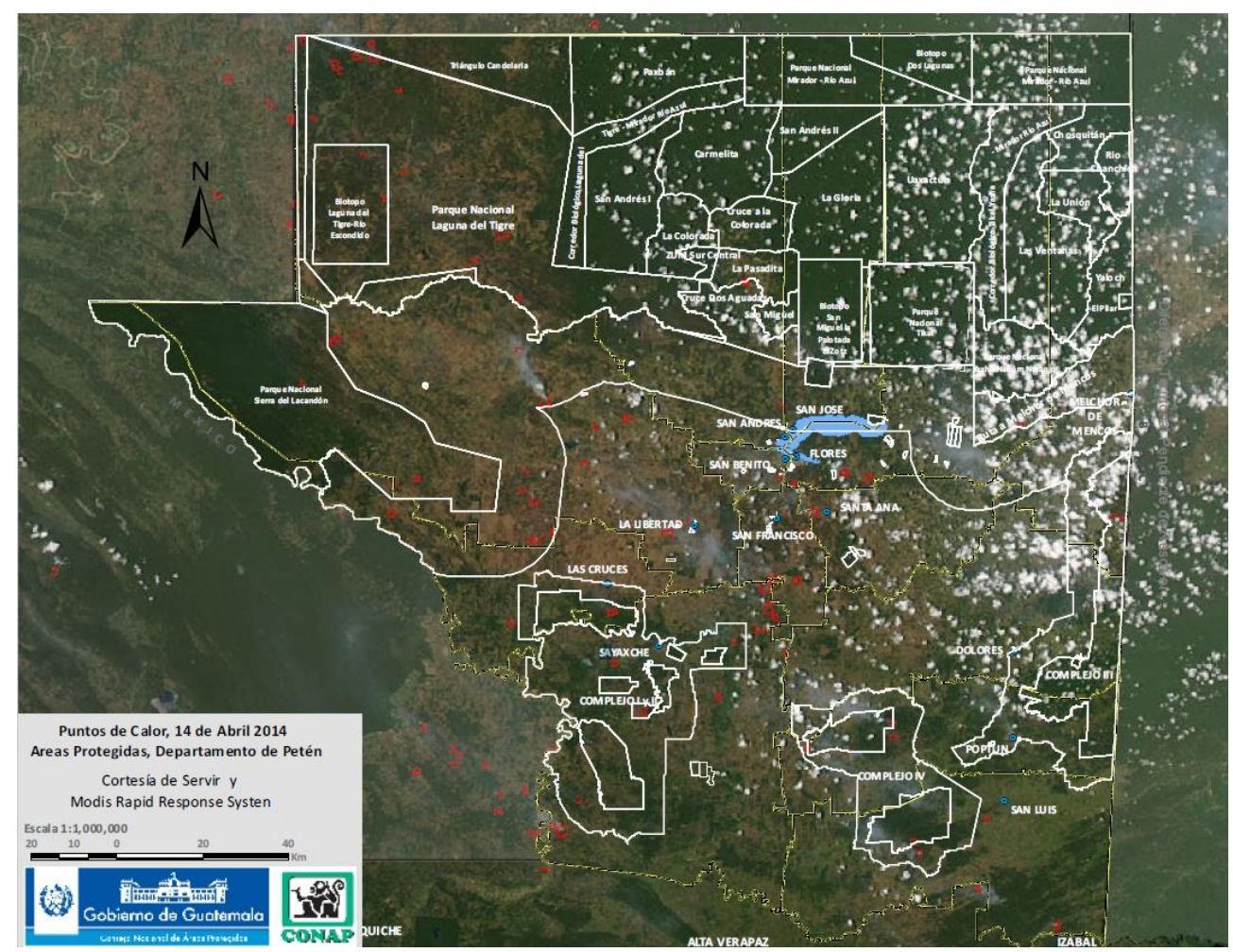

Figure 2. Sample hotspot map distributed by CEMEC on 14 April 2014 (courtesy of CEMEC).

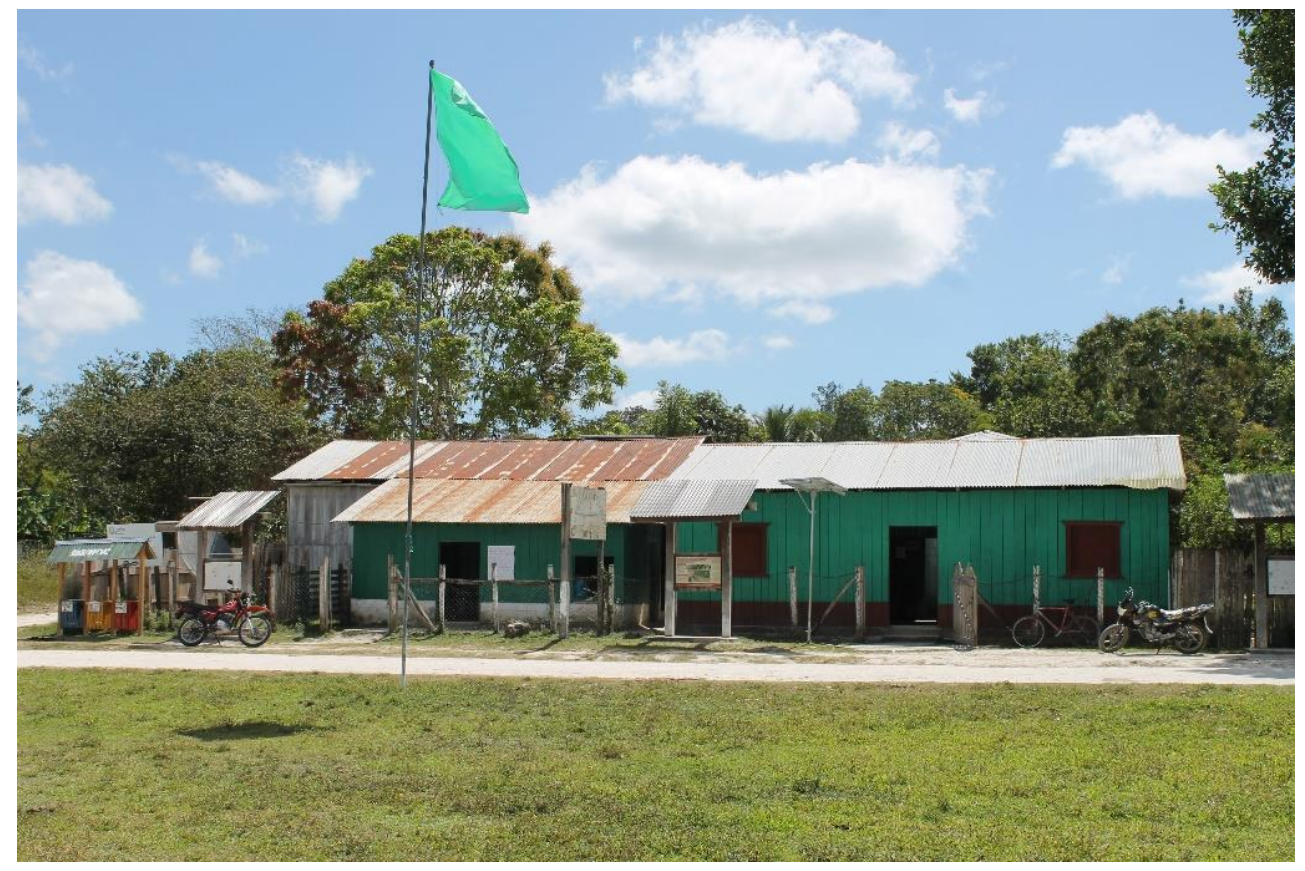

Figure 3. In Uaxactún, Petén, the local Management and Conservation Organization, known as OMYC, hangs a green flag indicating that climate conditions are low-risk for the spread of fire and that farmers may proceed with scheduled agricultural burnings (alternatively, a red flag would indicate that burning is not permitted). This communication system supplements the daily dissemination of hotspot maps-where hotspot locations do not coincide with planned burnings or are detected during no-burn periods, response teams are dispatched to locate and, if necessary, control the fire.

Field interviews and secondary data indicate that the use of SIGMA-I for early warning systems, responsible agricultural burning, and informed deployment of resources for forest 
fire prevention has contributed to significant improvements in forest fire management in Petén. Forest fire response data provided by INAB, for example, indicate overall declines in cumulative surface area damaged by fire ("fire scarring"), surface area damaged within proximity to cultivated areas and forests, response time to forest fires, and resources required to control forest fires since 2006 [20]. The WCS officials noted that in the three communities where the WCS operates, as of 2015, no uncontrolled forest fires had occurred since the adoption of SIGMA-I [21].

Morrison et al. note: "A reduction in documented 'intentional' fires during this time further supports first-hand accounts from WCS and others that the use of geospatial imagery to detect fires improves community awareness and has a sensitization effect in Petén communities. Local residents are less likely to engage in illegal agricultural burning, for example, knowing that illicit fires are likely to be detected by CONAP and its partners [4,22]." Morrison et al. conclude that "critical to these successes is the fact that SIGMA-I and its hotspot maps are part of a larger pool of information that contributes to planning and decision-making regarding public-sector investment and institutional presence in Petén [4]." Other monitoring tools employed by CONAP and its partners include periodic aerial monitoring (particularly over isolated areas and during critical periods) and ground patrols to monitor fire activity and other threats such as deforestation and trafficking of wildlife and cultural artefacts $[4,5,22]$.

\subsection{Choice Experiment Methodology}

The frequent use of SIGMA-I hotspot maps to detect and mitigate fire activity indicates a positive value of the tool for decision-makers. As previously noted, SIGMA-I data are currently provided free of cost to Guatemalan end users by the USAID and the NASA. Estimates of the nonmarket value of SIGMA-I are thus useful for program evaluation and determining whether these data provide sufficient benefits to justify the costs. Furthermore, understanding the relative value of attributes of SIGMA-I can inform improvements in product development. We use a choice experiment methodology to estimate the nonmarket value of SIGMA-I.

The total economic value of an environmental good or service includes both market and nonmarket values. Market values are reflected in market prices, whereas nonmarket values must be estimated. Nonmarket valuation is an economic method of estimating values of goods and services not typically bought and sold in a market. Choice experiments are a stated preference method of nonmarket valuation. Choice experiments involve surveying a sample of relevant respondents regarding their preferences [23]. Respondents are asked questions within the context of a hypothetical market, wherein the good or service in question is composed of various attributes, including one cost attribute. Respondents are given a series of choice sets involving hypothetical scenarios with different levels of each attribute. Willingness to pay for the good or service is estimated through observing respondents' choices between options with varying levels of attributes [24,25].

Choice experiments are theoretically based on the well-established random utility model $[23,26]$. Random utility maximization assumes that when presented with a choice, respondents will choose the option that results in the highest benefits [27]. Therefore, for individual $i$ and alternative $j$, utility has a deterministic component $(V)$ and a stochastic component $(\varepsilon)$. According to the random utility theory, $\varepsilon$ exists because the researcher observes the choice between options, but the actual utility function remains unknown. Therefore, estimates of utility are probabilistic. We assume utility is linear in parameters, and thus:

$$
\begin{gathered}
U_{i j}=V_{i j}+\varepsilon_{j} \\
V_{i j}=x_{i j}^{\prime} \beta
\end{gathered}
$$

where $x i j$ are alternative-specific regressors [26] and $\beta$ is a vector of preference parameters representing marginal utilities. To obtain marginal utilities, we differentiate (2) with respect to the attributes $[26,28]$, and $\partial U_{j} / \partial x_{j}$ for the $k$ th attribute is equal to $\beta_{k}$. The ratios of $\beta_{k}$ 
represent marginal rates of substitution, and the marginal WTP for the $k$ th attribute $=$ $-\beta_{k} / \beta_{\text {price }} \gamma$ is a matrix of case-specific regression coefficients.

\subsection{Attribute Selection}

To select the attributes and attribute values for the model, the research team, with the support of local subject matter experts, visited Guatemala in February and March 2015 and again in March 2016 to observe the country's forest fire management systems and better understand the context and conditions under which SIGMA-I tools are used. Field site visits intentionally coincided with the onset of the forest fire season, when the respondents were most likely to be actively deploying SIGMA-I tools, and thus best able to assign relative value to their attributes. Interviews were conducted with CEMEC and other stakeholders involved in the development, dissemination, and use of the hotspot maps at all levels of government, including decision-makers in Guatemala City; Flores, Petén, where departmental forest management organizations are based; and forest fire-vulnerable communities in Uaxactún and Corozal in Petén. As the final step, the research team piloted the choice experiment survey instrument with stakeholders at each level. Table 1 provides a list of key informants whose input contributed to attribute selection.

Table 1. Participating organizations and locations.

\begin{tabular}{cc}
\hline Organization & Location \\
\hline Center for Conservation Studies (CECON), University of San Carlos & Guatemala City \\
\hline National Protected Areas Council (CONAP) & Guatemala City \\
\hline System for the Prevention and Control of Forest Fires (SIPECIF) & Guatemala City \\
\hline $\begin{array}{c}\text { Defenders of Nature Foundation (Fundación Defensores de la Naturaleza) (FDN) } \\
\text { (Sierra del Lacandón National Park) }\end{array}$ & Flores, Guatemala \\
\hline Monitoring and Evaluation Center (CEMEC) & Flores, Guatemala \\
\hline Propetén & Flores, Guatemala \\
\hline Wildlife Conservation Society (WCS) & Flores, Guatemala \\
\hline Corozal Forest Fire Council & Corozal, Guatemala \\
\hline Management and Conservation Organization (OMYC) & Uaxactún, Guatemala \\
\hline Yaxha & Yaxha-Nakum-Naranjo \\
\hline
\end{tabular}

Of the suite of SIGMA-I products and tools, field interviews consistently indicated that hotspot maps are the most widely disseminated, recognized, and utilized SIGMA-I product $[17,29,30]$. The choice experiment thus focuses on attributes most closely associated with the hotspot maps. Based on extensive field interviews, the research team identified five attributes of hotspot maps that are most likely to influence the utility of the hotspot data for its users. These attributes include the following, in no particular order:

1. Spatial resolution: In remote and difficult-to-access areas, the geographic precision of hotspot locations was commonly the most important attribute identified by the respondents during in-person interviews. At the time the choice experiment was conducted, MODIS hotspot maps located thermal anomalies with a $1 \mathrm{~km}$ spatial resolution, meaning one hotspot coordinate denotes the center of a $1 \mathrm{~km} \times 1 \mathrm{~km}$ pixel (or plot) of land irrespective of fire size or number of fires within that pixel. NASA sums up the tradeoffs between the detection confidence and the rate of detection as follows: "In some applications errors of commission (or false alarms) are particularly undesirable, and for these applications one might be willing to trade a lower detection rate to gain a lower false alarm rate. Conversely, for other applications missing any 
fire might be especially undesirable, and one might then be willing to tolerate a higher false alarm rate to ensure that fewer true fires are missed. Users requiring fewer false alarms may wish to retain only nominal- and high-confidence fire pixels, and treat low-confidence fire pixels as clear, non-fire, land pixels. Users requiring maximum fire detectability who are able to tolerate a higher incidence of false alarms should consider all three classes of fire pixels" [31].

2. Temporal resolution: Temporal resolution, or the frequency with which hotspot data can be processed and disseminated to first responders, is a determining factor for whether a fire is detected within hours, days, or a week's time.

3. Accuracy: False positives, or hotspot alerts where no fire exists, can and do happen and may affect users' confidence in the hotspot data. False positives (and negatives) may be correlated, if not attributed, to spatial resolution. That correlation will be weak, however, given that spatial resolution is adequately precise such that false positives relating to lack of precision are rare. The respondents in the MBR could not say how common false positives are, but most respondents could provide at least one example of a false alarm that caused an expense of human or material resources to respond to a thermal anomaly for which a corresponding fire was never found.

4. Land use/land cover mapping: Land use and land cover information can provide planners and responders with a sense of where fires are likely to occur and how quickly they will spread. CONAP officials at the departmental level in Petén, for example, touted the value of land use and fire scarring maps for monitoring agricultural activities in concession communities and identifying areas vulnerable to fire in their annual operative plan [19]. Likewise, park officials in the Laguna del Tigre National Park cross-reference hotspot maps with risk maps demarcating land cover that is sensitive to fire [8].

5. Climate forecast: At the time of the choice experiment, in addition to known hotspot locations, CEMEC's weekly fire reports included accumulated precipitation, drought (using the Keetch-Byram drought index), and climate forecast data. The respondents commonly identified climate variables as the key factors in determining their state of alert. Officials in the Laguna del Tigre National Park, for example, referenced a "30-30-30" rule to describe extreme fire risk conditions: temperatures over $30{ }^{\circ} \mathrm{C}$, relative humidity below $30 \%$, and wind velocity greater than $30 \mathrm{~km} / \mathrm{h}$ [8].

\subsection{Construction of the Cost Attribute}

The final attribute to be considered in the choice experiment design is cost. The Guatemalan context and structure of the forest fire management system pose unique challenges for constructing the cost attribute. First, end users of the hotspot maps often do not make budgetary decisions for forest fire management. There is administrative separation between central- or department-level government officials with budgetary authority and operational personnel responsible for actions in the field. As noted above, local forest fire committees have a contractual obligation to respond to fire threats as part of the concession agreements that permit the use of protected lands for agriculture or other resource extraction. According to ProPetén, however, total allocation for forest fire response at the community level is typically not more than Q3000/season [30]. Second, with few exceptions, first responders are comprised primarily of volunteers. They are likely to receive hotspot maps only through an intermediary, such as the WCS or ProPetén, and only in the event of a fire. They are thus unlikely to have knowledge of the relative utility or value of the various attributes of the hotspot maps for hotspot response $[22,30]$.

For these reasons, the research team opted to structure the cost levels to target intermediary, regional, or central decision-makers based on respondents' budgetary decisionmaking authority. In assigning a range of values for the cost attribute, the research team set the following parameters:

1. Cost options were framed as an annual service fee, as opposed to monthly fee, to account for variance in fire incidence across months during a single fire season. 
2. The median cost was based on the expected mean willingness to pay, which was calculated as a function of the cost of Internet services in Petén. According to the respondents in Uaxactún, the cost of one month's Internet service was approximately Q600 at the time of the study [18]. Half that value, amortized over four months (the average length of one fire season), is equal to Q1200.

3. The maximum randomized cost option reflected a three-fold increase in the expected mean, rounded to the nearest thousand quetzales, or Q4000 (the maximum needs to be high enough for people to decide not to pay).

4. In the same way, the maximum randomized cost option was intentionally high, the minimum-intentionally low. The minimum randomized cost option reflected the equivalent of $\$ 1 /$ month, or Q30.

\subsection{Development of Attribute Choice Sets}

The choice experiment, conducted through an online survey, asked stakeholders to express preference among various design options of the hotspot mapping product. Each option, or "choice set", represented a combination of select product attributes. In consultation with practitioners familiar with the product, the attributes comprising the choice sets were selected, defined, and assigned varying levels. By selecting from sets of combinations of attributes, the respondents made implicit tradeoffs and, in so doing, identified the product attributes that provide them with maximum utility. For our choice experiment, the third choice (Option "C") represented the current status quo of attributes of SIGMA-I.

Each choice set was designed to have different levels of specific attributes (Table 2). The levels of attributes were randomly assigned using an algorithm that ensured efficient combinations of attributes per each choice set. For the cost attribute, intervals between the minimum, the expected mean, and the maximum were intentionally not evenly spaced. Each respondent answered a series of 10 choice sets. Table 3 presents an example choice set.

Table 2. Choice set attributes, units, and levels.

\begin{tabular}{ccc}
\hline Attribute & Units & Levels \\
\hline Spatial resolution & Meters & $100,500,1000 *$ \\
Frequency of reporting & Time & Twice daily, daily ${ }^{*}$, weekly \\
Climate forecast & Days of advanced notice & Current day, 8 days $*, 15$ days \\
Land use/land cover mapping & Time & Weekly, biweekly*, seasonal \\
Accuracy & Percentage of false positives & $5 \%, 15 \% *, 25 \%$ \\
Cost & Quetzales & $200,500,1200,2000,2600,3300,4000$ \\
\hline
\end{tabular}

${ }^{*}$ Indicates the status quo option $C$. The cost of option $C=0$.

Table 3. Example choice set.

\begin{tabular}{cccc}
\hline & A & B & C (Status Quo) \\
\hline Spatial resolution & $100 \mathrm{~m}$ & $500 \mathrm{~m}$ & $1000 \mathrm{~m}$ \\
Frequency of reporting & Twice daily & Daily & Daily \\
Climate forecast & 8 days of advanced notice & 15 days of advanced notice & 8 days of advanced notice \\
Land use/land cover mapping & Weekly & Biweekly & Monthly \\
Accuracy & $5 \%$ of false positives & 25\% of false positives & $15 \%$ of false positives \\
Annual cost & Q3300 & Q1200 & 0 \\
\hline
\end{tabular}

\section{Results}

\subsection{Results of the Model}

The choice experiment was sent to 85 respondents in 2016, resulting in 2550 complete observations. Because the utility function is probabilistic, limited dependent variable estimation techniques are necessary to estimate the econometric model. We used a conditional logit model to predict the probability of a respondent choosing a particular option. 
We estimated the conditional logit using the maximum likelihood. We included all the attributes as explanatory variables. We also included an alternative specific constant (status quo) variable. Status quo is the alternative specific constant, with a mean of 0.37 , indicating that $37 \%$ of the choice sets resulted in the "status quo" option being preferred (Table 4). Our results generally conform to the law of demand. As the cost increased, the percentage of "yes" choices decreased, with the exception of the highest price point (Figure 4).

Table 4. Summary statistics for explanatory variables.

\begin{tabular}{|c|c|c|c|c|c|}
\hline Variable & Observations & Mean & $\begin{array}{l}\text { Standard } \\
\text { Deviation }\end{array}$ & Minimum & Maximum \\
\hline Spatial resolution & 2330 & 702.40 & 370.04 & 100 & 1000 \\
\hline Frequency of reporting & 2330 & 2.00 & 0.65 & 1 & 3 \\
\hline Climate forecast & 2330 & 8.02 & 4.54 & 1 & 15 \\
\hline Land use/land cover mapping & 2330 & 2.00 & 0.65 & 1 & 3 \\
\hline Accuracy & 2330 & 0.15 & 0.07 & 0.05 & 0.25 \\
\hline Annual cost & 2330 & 1054.08 & 1341.78 & 0 & 4000 \\
\hline Status quo & 2550 & 0.37 & 0.48 & 0 & 1 \\
\hline
\end{tabular}

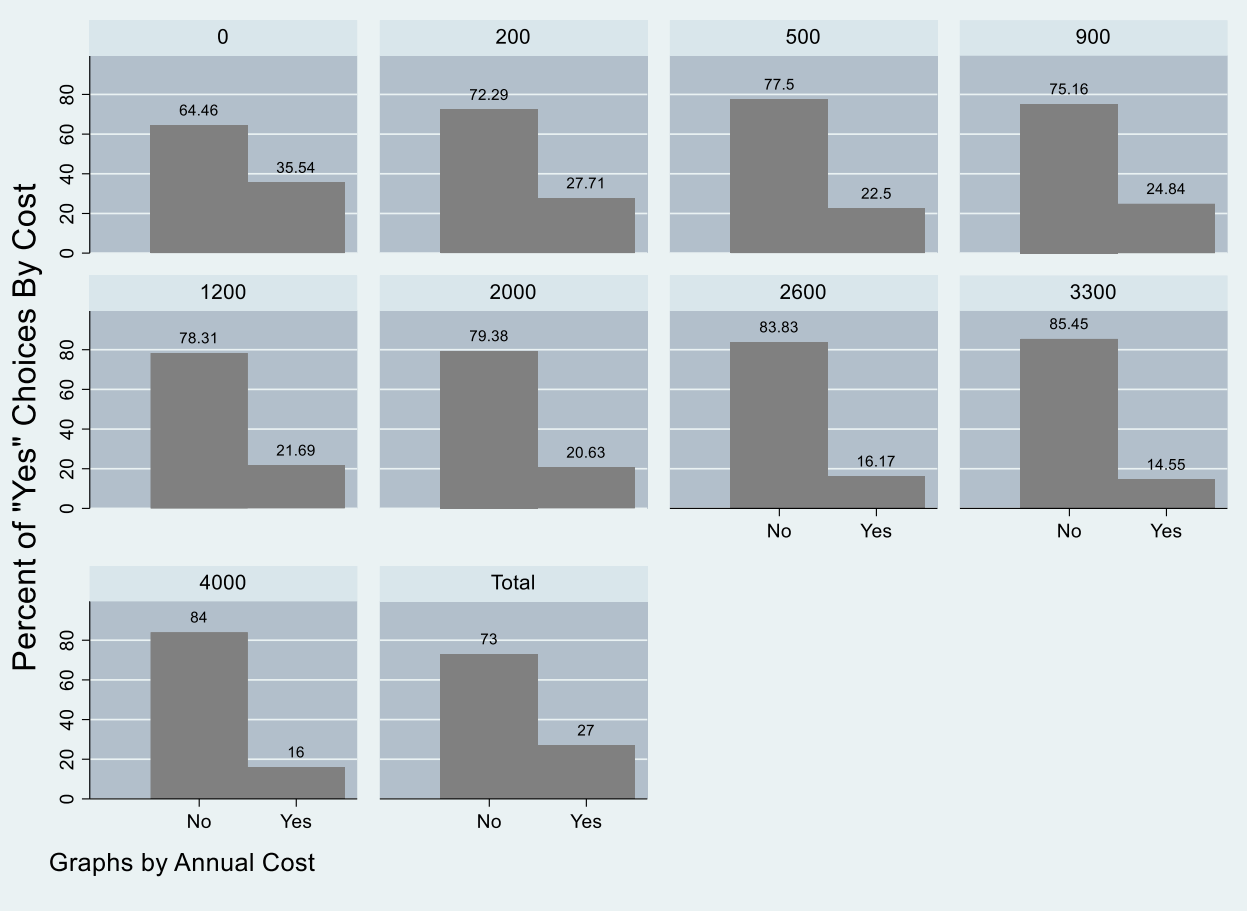

Figure 4. Percent of "yes" choices by the annual cost.

The conditional logit shows positive estimated coefficients on all the variables except the annual cost. An increase in the level of each attribute, holding all others constant, will result in an increase in the probability of a "yes" choice for that option. An increase in the annual cost, all else constant, will result in a decrease in the probability of a "yes" choice for that option (Table 5). 
Table 5. Conditional logit results.

\begin{tabular}{|c|c|c|}
\hline & Variable & Estimated Coefficient \\
\hline & Resolution & $\begin{array}{c}0.000249 \\
(1.74)\end{array}$ \\
\hline & Frequency & $\begin{array}{c}0.189436 \\
(2.44)^{*}\end{array}$ \\
\hline & Forecast & $\begin{array}{c}0.013316 \\
(1.19)\end{array}$ \\
\hline & Deforestation & $\begin{array}{c}0.130323 \\
(1.66)\end{array}$ \\
\hline & Error & $\begin{array}{l}0.034505 \\
(4.39)^{* *}\end{array}$ \\
\hline & Cost & $\begin{array}{c}-0.000379 \\
(8.26)^{* *}\end{array}$ \\
\hline & Status quo & $\begin{array}{l}0.630236 \\
(6.48)^{* *}\end{array}$ \\
\hline$n$ & & 2330 \\
\hline
\end{tabular}

Standard errors in parentheses, ${ }^{*} p<0.05 ;{ }^{* *} p<0.01$.

\subsection{Willingness to Pay Estimates}

Our results indicate that frequency of reporting and reductions in false positives are the most important attributes of the hotspot monitoring system. Land cover mapping, climate forecast, and land use cover are not statistically significant in the model. However, the implied ranking of the attributes based on willingness to pay is statistically significant (with 1 being the most important):

1. Frequency of reporting;

2. Reduction in false positives;

3. Land use/land cover mapping;

4. Climate forecast;

5. Spatial resolution.

The highest marginal willingness to pay was for an increase in the frequency of reporting. We found a positive and statistically significant willingness to pay for improvements in the frequency of reporting and reductions in false positives. Table 6 shows the willingness to pay results in quetzales for the two statistically significant attributes, with the lower and upper bounds of the $95 \%$ confidence interval. In other words, the average willingness to pay for an increase in the frequency of reporting was Q500 (US\$64). The average willingness to pay for a reduction in the percentage of false positives was Q91 (US\$12).

Table 6. Willingness to pay (WTP) results (quetzales).

\begin{tabular}{cccc}
\hline & WTP & Lower 95\% CI & Upper 95\% CI \\
\hline Frequency of reporting & 500 & 85 & 914 \\
Percentage of false positives & 91 & 48 & 135 \\
\hline
\end{tabular}

\section{Discussion}

Our data provide statistically significant results that the SIGMA-I hotspot monitoring tool has positive nonmarket benefits for product users. Our results show that the frequency of reporting has the highest relative value for our respondents, followed by reductions in false positives. In other words, respondents valued information that allowed for a timely and cost-effective response to forest fire detection. The choice experiment largely bears out expectations of value based on field interviews and observation: namely, that geospatial data permit fire management authorities to monitor a large and densely forested administrative area in near-real time with limited resources. The unique focus of the choice experiment to estimate benefits of a particular product in a developing country via an email survey limits the generalizability of our willingness to pay estimates to a larger 
sample. However, value estimates of attributes included in this choice experiment can inform investments in future product development and provision to maximize value of similar products in other contexts.

Previous research in nonmarket valuation similarly shows a positive willingness to pay for Landsat imagery provided by the United States Geological Survey to domestic and international users free of cost. Straub et al. found an average economic benefit per Landsat image of US $\$ 203$ per international user using the contingent valuation method [14]. While our willingness to pay estimates are lower than the estimated values for Landsat imagery [12-14], the beneficiaries of the hotspot maps include product users and community members at large who benefit from improved fire management. Therefore, the willingness to pay for attributes of SIGMA-I is a lower bound estimate of the potential societal value of the provision of the hotspot monitoring tool. In addition, our survey respondents answered questions based on their workplace budget constraints (as a benchmark comparison, one CONAP official in Guatemala City who is responsible for budgetary decisions felt that the SIGMA-I tools were "priceless" given an alternative scenario of managing agricultural burning and forest fire risk without them [19]).

Our study focused on fire managers in Guatemala; however, our results have broader implications for regions where fire management is dependent upon internationally funded geospatial analysis tools. We provide quantitative evidence of the positive value of geospatial tools and the necessity of continued funding and provision of geospatial data. Importantly, we also shed light on how satellite data are used in practice to complement other forest fire management tools. Such insights can help guide how product developers introduce data products and tools to new user communities, encourage adoption, build user capacity, and tailor product functionality to user contexts and needs.

Finally, the relevance of the insights derived from this study underscore the viability of a choice experiment as a methodological approach for assessing the value of comparable geospatial resources in other developing countries. While the choice experiment remains valuable in communicating relative values of attributes of the product, obtaining the total economic value of the product would involve surveying community members about the value of improved fire management as a result of using SIGMA-I. Future research that incorporates the relative benefit to the community from improved management by surveying community members and potentially estimating costs of alternative management scenarios would complement our results. As improvements in technology and availability of satellite data continue, new points of comparison will emerge for determining the conditions for which satellite data are of greatest value.

Supplementary Materials: Additional information on the use of SIGMA-I in Guatemala can be found in the two SERVIR Global evaluation reports published by the USAID Development Experience Clearinghouse (DEC) in 2017 and available online at https:/ / pdf.usaid.gov / pdf_docs/PBAAJ721.pdf (accessed 27 October 2021) [4] and https:/ / pdf.usaid.gov/pdf_docs/PBAAJ722.pdf (accessed on 27 October 2021) [5].

Author Contributions: Conceptualization, I.M. and J.B.; methodology, J.M.M.; software, J.M.M.; validation, J.M.M. and J.B.; formal analysis, J.M.M. and J.B.; investigation, I.M. and J.B.; resources, I.M.; data curation, J.M.M.; writing—original draft preparation, J.M.M. and J.B.; writing-review and editing, J.B. and I.M.; visualization, J.M.M.; supervision, I.M.; project administration, I.M. All authors have read and agreed to the published version of the manuscript.

Funding: The data used in this paper were collected as part of a performance evaluation conducted by Management Systems International, a Tetra Tech company, and by Development and Training Services, a Palladium company. The evaluation research was funded by the United States Agency for International Development (USAID) under the Bureau for Economic Growth, Education, and Environment (E3) Analytics and Evaluation Project (Contract No. AID-OAA-M-13-00017). The views and opinions expressed in this paper are those of the authors and not necessarily the views and opinions of the United States Agency for International Development. This paper was prepared independently from that performance evaluation and received no additional external funding. 
Institutional Review Board Statement: Ethics review and approval were waived for this study as it falls under exemption category 5 under the US Federal Government's HHS 45 CFR 46.101(b) common rule requirements, namely, "Research and demonstration projects which are conducted by or subject to the approval of department or agency heads, and which are designed to study, evaluate, or otherwise examine: (a) public benefit or service programs; (b) procedures for obtaining benefits or services under those programs; (c) possible changes in or alternatives to these programs or procedures; or (d) possible changes in methods or levels of payment for benefits or services under those programs." All the individuals participating in survey procedures, interview procedures, or observation of public behavior were elected or appointed public officials, and the confidentiality of all the individual personally identifiable information was maintained throughout the research and thereafter.

Informed Consent Statement: Informed consent was obtained from all the subjects involved in the study.

Data Availability Statement: The data are available on request. The data are not publicly available due to the US Government's data privacy protocols. To protect the privacy of the respondents, the authors provided the names of organizations that participated in the study. Individual names are omitted.

Acknowledgments: The authors would like to thank Margarita Vides for her invaluable expertise and support in the field; Molly Hageboeck, Bhavani Pathak, and Carolyn Fonseca for enabling this research; Victor Hugo Ramos of CEMEC-CONAP for his tireless assistance; and the entire SERVIR team at the USAID and the NASA for their technical assistance, enthusiasm, and curiosity.

Conflicts of Interest: The authors declare no conflict of interest.

$\begin{array}{ll}\text { Glossary of Acronyms } \\ \text { CEMEC } & \text { Center for Monitoring and Evaluation (at CONAP) } \\ \text { CONAP } & \text { National Council for Protected Areas } \\ \text { CONRED } & \text { Guatemala Coordinating Agency for Disaster Reduction } \\ \text { INAB } & \text { National Forestry Institute } \\ \text { MODIS } & \text { Moderate Resolution Imaging Spectroradiometer } \\ \text { MBR } & \text { Maya Biosphere Reserve } \\ \text { MUZ } & \text { Multiuse Zone (within the Maya Biosphere Reserve) } \\ \text { NASA } & \text { National Aeronautics and Space Administration } \\ \text { SIGMA-I } & \text { Geospatial Information System for Fire Management } \\ \text { SIPECIF } & \text { National Forest Fire Prevention and Control System } \\ \text { USAID } & \text { United States Agency for International Development } \\ \text { WCS } & \text { Wildlife Conservation Society }\end{array}$

\section{References}

1. SERVIR Global. Geospatial Information System for Fire Management (SIGMA-I) in Guatemala. 2010. Available online: https: / / servirglobal.net/Global/Articles/Article/852/geospatial-information-system-for-fire-management-sigma-i-in-guatemala (accessed on 30 May 2021).

2. United Nations Educational, Scientific, and Cultural Organization. Maya Biosphere Reserve, Guatemala. 2019. Available online: https:/ / en.unesco.org/biosphere/lac/maya (accessed on 27 October 2021).

3. Monzón-Alvarado, C.; Cortina-Villar, S.; Schmook, B.; Flamenco-Sandoval, Z.C.; Arriola, L. Land-use decision-making after large-scale forest fires: Analyzing fires as a driver of deforestation in Laguna del Tigre National Park, Guatemala. Appl. Geogr. 2012, 35, 43-52. [CrossRef]

4. Morrison, I.; Berenter, J.; Mueller, J.; Mbeche, R.; Jomo, J.; Vides, M. SERVIR Performance Evaluation: Evaluation Question 1 Report; United States Agency for International Development (USAID): Washington, DC, USA, 2017. Available online: https: //pdf.usaid.gov/pdf_docs/PBAAJ721.pdf (accessed on 27 October 2021).

5. Morrison, I.; Berenter, J.; Mueller, J.; Mbeche, R.; Jomo, J.; Vides, M. SERVIR Performance Evaluation: Evaluation Question 3 Report; United States Agency for International Development (USAID): Washington, DC, USA, 2017. Available online: https: //pdf.usaid.gov/pdf_docs/PBAAJ722.pdf (accessed on 27 October 2021).

6. SIPECIF Representative, Interviewed by Author, Guatemala City, Guatemala. April 2016.

7. Barmpoutis, P.; Papaioannou, P.; Dimitropoulos, K.; Grammalidis, N. A Review on Early Forest Fire Detection Systems Using Optical Remote Sensing. Sensors 2020, 20, 6442. [CrossRef] [PubMed] 
8. Representative from Laguna del Tigre National Park Office of the Director, Interviewed by Author, Flores, Guatemala. March 2016.

9. Johnson, L.; Easson, G. Use of NASA Satellite Assets for Predicting Wildfire Potential for Forest Environments in Guatemala; Mississippi Mineral Resources Institute: Oxford, MS, USA, 2008. Available online: http://mmri.olemiss.edu/Home/projects/docs/2008-0628-003.aspx (accessed on 30 May 2021).

10. Rodríguez-Trejo, D.A.; Martínez-Hernández, P.A.; Ortiz-Contla, H.; Chavarría-Sánchez, M.R.; Hernández-Santiago, F. The Present Status of Fire Ecology, Traditional Use of Fire, and Fire Management in Mexico and Central America. Fire Ecol. 2011, 7, 40-56. [CrossRef]

11. SERVIR. About SERVIR. Available online: https:/ / servirglobal.net/\#aboutservir (accessed on 30 May 2021).

12. Miller, H.M.; Richardson, L.; Koontz, S.R.; Loomis, J.; Koontz, L. Users, uses, and value of Landsat satellite imagery-Results from the 2012 survey of users. In United States Geological Survey Numbered Series; Open-File Report 2013-1269; USGS: Reston, VA, USA, 2013; p. 51. [CrossRef]

13. Miller, H.M.; Sexton, N.R.; Koontz, L.; Loomis, J.; Koontz, S.R.; Hermans, C. The users, uses, and value of Landsat and other moderate-resolution satellite imagery in the United States-Executive report. In United States Geological Survey Numbered Series; Open-File Report 2011-1031; USGS: Reston, VA, USA, 2011. Available online: https: //www.researchgate.net/profile/Holly_Miller4/publication/260480636_The_Users_Uses_and_Value_of_Landsat_and_ Other_Moderate-Resolution_Satellite_Imagery_in_the_United_States-Executive_Report/links/02e7e53166790c27b9000000.pdf (accessed on 27 October 2021).

14. Straub, C.L.; Koontz, S.R.; Loomis, J.B. Economic valuation of Landsat imagery. In United States Geological Survey Numbered Series; Open-File Report 2019-1112; USGS: Reston, VA, USA, 2019; p. 13. [CrossRef]

15. Radachowsky, J.; Ramos, V.; McNab, R.; Baur, E.; Kazakov, N. Forest concessions in the Maya Biosphere Reserve, Guatemala: A decade later. For. Ecol. Manag. 2012, 268, 18-28. [CrossRef]

16. Koonce, A.L.; González-Cabán, A. Social and Ecological Aspects of Fire in Central America. In Fire in the Tropical Biota; Ecological Studies (Analysis and Synthesis); Goldammer, J.G., Ed.; Springer: Berlin/Heidelberg, Germany, 1990. [CrossRef]

17. Representatives from Center for Monitoring and Evaluation (CEMEC), National Council for Protected Areas (CONAP); Wildlife Conservation Society (WCS); and ProPetén. Interviewed by author, Flores, Guatemala. April 2016.

18. Members of fire management councils, Uaxactún and Corazal. Interviewed by author, Uaxactún and Corazal, Guatemala. April 2016.

19. Members of National Council for Protected Areas (CONAP). Interviewed by author, Guatemala City, Guatemala. February 2015.

20. Representative from National Forestry Institute. Interviewed by author, Guatemala City, Guatemala. March 2015.

21. Representative from Wildlife Conservation Society (WCS). Interviewed by author, Flores, Guatemala. March 2015.

22. Representative from Wildlife Conservation Society (WCS). Interviewed by author, Flores, Guatemala. April 2016.

23. Holmes, T.P.; Adamowicz, W.L.; Carlsson, F. Choice experiments. In A Primer on Nonmarket Valuation; Champ, P.A., Boyle, K.J., Brown, T.C., Eds.; Springer: Dordrecht, The Netherlands, 2017; pp. 235-292.

24. Hanley, N.; Mourato, S.; Wright, R.E. Choice modelling approaches: A superior alternative for environmental valuation? J. Econ. Surv. 2001, 15, 435-462. [CrossRef]

25. Hoyos, D. The state of the art of environmental valuation with discrete choice experiments. Ecol. Econ. 2010, 69, 1595-1603. [CrossRef]

26. Louviere, J.J.; Hensher, D.A.; Swait, J.D. Stated Choice Methods: Analysis and Applications; Cambridge University Press: Cambridge, $\mathrm{UK}, 2000$.

27. Cameron, A.C.; Trivedi, P.K. Microeconometrics Using Stata; Stata Press: College Station, TX, USA, 2010.

28. Holmes, T.P.; Adamowicz, W.L. Attribute-Based Methods. In A Primer on Nonmarket Valuation; Champ, P.A., Boyle, K.J., Brown, T.C., Eds.; Kluwer Academic Publishers: Dordrecht, The Netherlands, 2003.

29. Representatives from Center for Monitoring and Evaluation (CEMEC). Interviewed by author, Flores, Guatemala. March 2015.

30. Representative from ProPetén. Interviewed by author, Flores, Guatemala. April 2016.

31. NASA. FIRMS Frequently Asked Questions. Available online: https://earthdata.nasa.gov/faq/firms-faq (accessed on 30 May 2021). 